\title{
Heavy Precipitation in the Alpine Region (HERA): Areal Rainfall Determination for Flood Warnings Through in-situ Measurements, Remote Sensing and Atmospheric Modelling
}

\author{
H. Volkert \\ With 8 Figures \\ Received April 14, 1999 \\ Revised August 3, 1999
}

\begin{abstract}
Summary
Background and key results of the EU-funded project HERA are presented. The identification of the growing possibilities to use forecast precipitation fields as input for hydrological models is followed by a broad assessment of the state of the art regarding the determination of the atmospheric part of the hydrological cycle, with the geographical focus on the mountainous region of the Alps in the heart of Europe. This includes the construction of (north)Alpine radar composites for nine episodes; a first systematic cross-validation on a daily basis of four operational forecasting models with a trans-national gridded observational dataset; several detailed case studies involving research versions of operational forecast models and the latest advances in model resolution and microphysical parameterizations; new algorithms for Doppler radar retrievals over complex terrain; and synthetic modelling studies with governing parameters derived from the selected cases to investigate some basic processes in isolation. Finally, implications for proto-type applications of forecast areal precipitation fields in the hydrological modelling of mountainous catchments are given.
\end{abstract}

\section{Introduction}

The picture of a hydrological cycle as an abstract, but persuasive concept for the movement and distribution of water in all its three phases within the layers above, at and below the Earth's surface is of such a basic nature that it features prominently already in primary school curricula. But its extremely complex and variable spatio-temporal nature renders its quantitative description an as yet unreached but important goal of basic and applied research.

Extreme cases of long lasting precipitation events and resulting floods are recorded in ancient, prescientific reports (e.g., about the Deluge, O.T., 1st book Mose 7, 17-24) or have repeatedly spurred institutional efforts regarding a better management during hazardous situations or even reliable warnings before such events. In Bavaria, for instance, meteorological and hydrotechnical institutes had been separately inaugurated after 1878, when the devastating floods of 1899 were followed by an increase of staff in all provinces of the kingdom and eventually by a cooperative agreement concerning flood warnings in 1910 (Volkert, 1983, pp. 65, 70, 203).

The European Commission included "flood hazard" in its portfolio of research programmes in 1986 (Casale et al., 1998), embedded into the more general theme of "natural risk and civil protection" (Horlick-Jones, 1995). The severe winter floods of Rhine and Meuse in 1993/94 and 1995 were taken as a timely reminder for even closer coordinated efforts and led to the inception of the Concerted Action "river basin modelling, management and flood mitigation 
(RIBAMOD)" (Moore, 1998). In parallel some 20 research projects obtained European funding under the heading "technologies to forecast, prevent and reduce hydrological and hydrogeological risks" within the "environment and climate" part of the Fourth Framework Programme.

The present state of affairs may be sketched as follows:

a) flood hazard is an old, clearly recognized problem area calling for a truely interdisciplinary approach (Cluckie, 1998);

b) the one outstanding feature of flood assessment which is readily accepted is that it is very difficult (Cluckie and Han, 1995);

c) clear-cut splits in subdomains are necessary to make progress step by step and to aid cooperations across well defined interfaces; natural subdomains are specific scientific disciplines, various spatial domains or different temporal horizons.

One such subdivision is given in Fig. 1 and serves to put the studies of this volume into perspective. The very transient, i.e. time dependent, hand-over of water from the atmosphere to the various catchment areas of the topographically structured ground and its subsequent

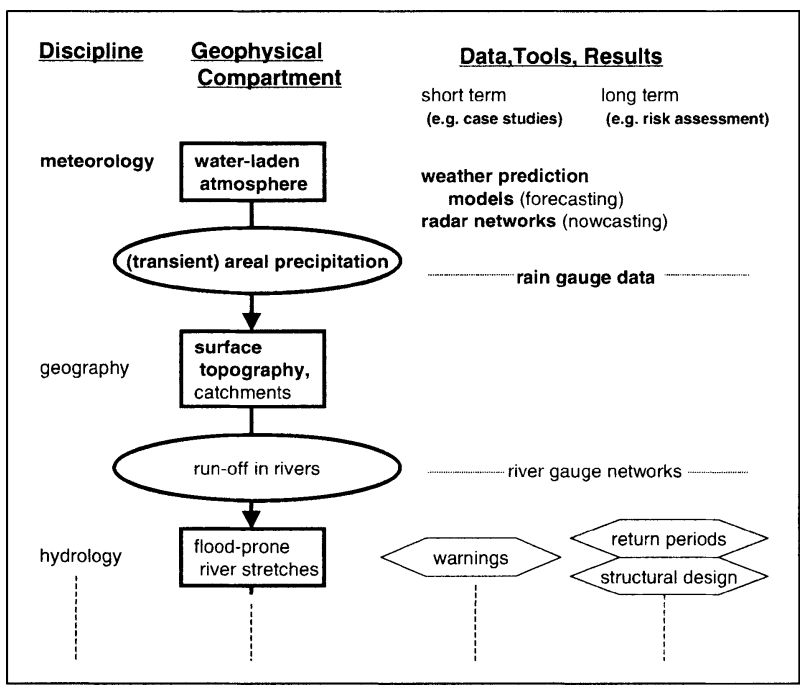

Fig. 1. Generic subdivision of the geophysical domain of the flood hazard issue into scientific disciplines, physical compartments (boxes) including the hand-over of water (ellipses), and the complex field spanned by data, tools, results (elongated diamonds) which inherently depends on the envisaged time horizon. The dots at the bottom point to other facets, e.g., socio-economic impacts. All aspects in bold face are dealt with in project HERA

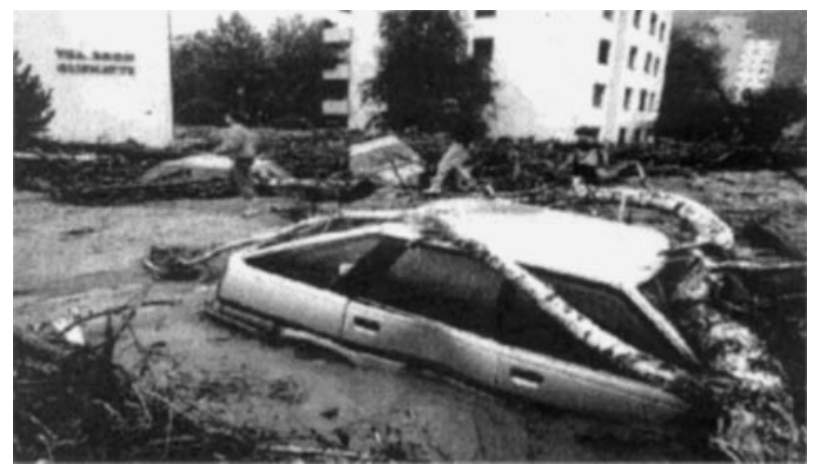

Photo: Coffrini; Sonntags-Zeitung of 26 Sept. 1993

Fig. 2. Cars buried in mud and uprooted trees after the devastating flash flood of the river Saltina in the town of Brig, Switzerland on 24 September 1993

collection in rivers (of lower dimensionality) is quite straight forward and somewhat in parallel to the established scientific disciplines meteorology, geography, and hydrology. Less evident is a consistent allocation of data, tools, and above all the desired results within such a framework.

A concentration on long term issues, such as risk assessment, calls for climatological time series of rain and river gauge networks, possibly augmented by a database of past floods (Garrote, 1995; Marcuello, 1998). This data in turn can be used to determine return periods, for predefined threshold values, to finally arrive at suitable designs of, e.g., urban canalisations or dams. Reliable flood warnings necessitate actual river level information from upstream gauges, possibly augmented by real-time estimates of areal precipitation from a radar network, depending on the scale and steepness of the catchment under consideration (Cluckie, 1999).

Considering the increasing skill and spatiotemporal resolution of numerical weather prediction (NWP) models, the vision of integrating forecast precipitation data into flood warning systems is both natural and demanding, especially for extended mountainous region such as the Alps in the heart of Europe. Ad-hoc feasibilty studies have dealt with such precipitation forecasts regarding flash floods in mountainous terrain (Quiby and Schubiger, 1998) and the simulation of the longer lasting extended precipitation system which caused the Oder flood of July 1997 (Keil et al., 1999).

The Alps are generally regarded as Europe's "water tower", as they serve to enhance the 


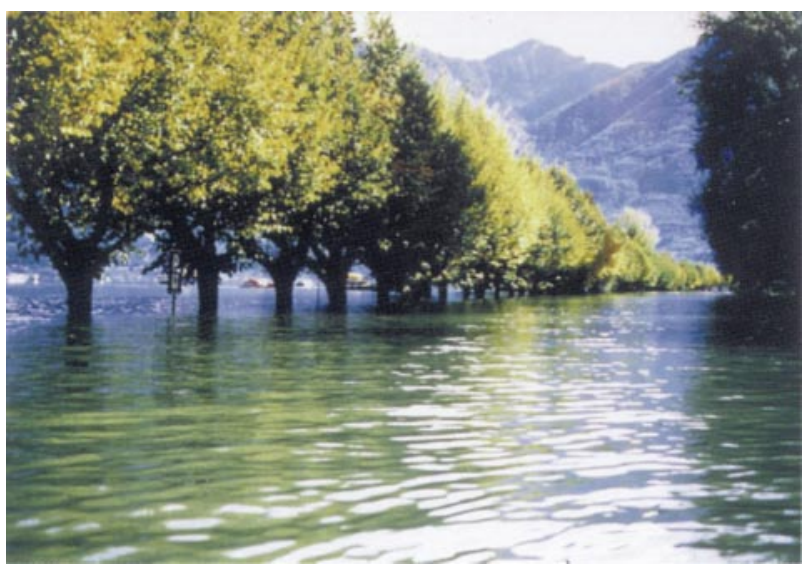

Photo: Rita Tognini

Fig. 3. 9 October 1993: Inundation of the lake-side promenade of Locarno at the northern shore of Lago Maggiore. The lake level was $3.7 \mathrm{~m}$ above normal due to about $800 \cdot 10^{6} \mathrm{~m}^{3}$ of excess water

ambient rainfall (as every major mountain range) and feed it into the large river systems of Rhône, Rhine, Danube, Po and their respective tributaries. Frei and Schär (1998) recently presented a first consistent, quality controlled 20 year precipitation climatology which made use of more than 6600 stations from various networks within the different Alpine countries. Among the outstanding results were the quantifications of maxima in both the mean precipitation $(>1800 \mathrm{~mm} / \mathrm{a})$ and its standard deviation at the northern and southern flanks of the massif and their distribution in a spotty pattern rather than in a uniform zone.

These climatological precipitation maxima are to some extent made up of singular episodes of extremely high rainfall amounts over comparatively short time periods. A frequent consequence are (flash) flood situations, which can lead to quite unexpected and severe consequences as in Brig, when on 24 September 1993 masses of gravel and mud suddenly filled the dammed bed of river Saltina and then spilled over into the town centre (Fig. 2). After continuing strong precipitation the water level of the neighboring Lago Maggiore on the region's south side had risen by $3.7 \mathrm{~m}$ some two weeks later (Fig. 3). The location and size of the lake $\left(212 \mathrm{~km}^{2}\right)$ embedded within the complex topography of southern Switzerland and adjacent Italy is visualized in Fig. 4.

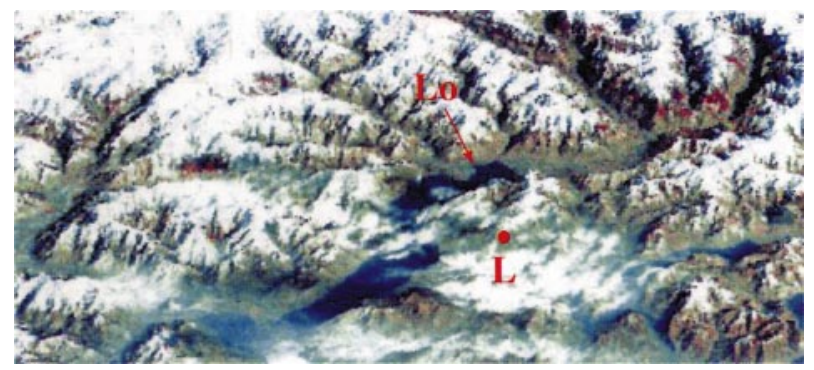

Picture: David Bresch with ARGOS software

Fig. 4. Elevated view from the south onto the region around Lago Maggiore (193 m MSL). Notable are the deep valleys with floor heights below $300 \mathrm{~m}$ between mountain ridges with snow covered summits in the range from 2000 to 3000 m. Locarno (Lo; Fig. 3) and Monte Lema radar site $(1620 \mathrm{~m}$; L; Fig. 8) are indicated in red

The database about natural disasters of Munich $\mathrm{Re}$, a large international reinsurance company, lists the following Alpine flood episodes as particularly severe disaster situations with profound socioeconomic impact: 20-22 September 1992 in the Alpine foothills of south-eastern France (38 deaths; main damages in the town Vaison-La-Romaine; economic losses exceeding $4 \cdot 10^{8}$ US\$); 20-28 September 1993 in the south-western Alps (16 deaths; large damages in the Swiss town Brig [see Fig. 2]; economic losses about $15 \cdot 10^{8}$ US\$); and 4-6 November 1994 in the Italian Piedmont region (64 deaths; economic losses exceeding 90 $10^{8}$ US\$).

During the 1990's the meteorological services, university departements and research laboratories in all Alpine countries became increasingly aware that the adequate observation of the rich range of mesoscale atmospheric phenomena instigated by the Alps, their basic understanding, and successful prediction constitute both difficult and desirable enterprises. Description and simulation of precipitation processes are one core topic of the ungoing "Mesoscale Alpine Programme (MAP)" (Binder and Schär, 1995), which will culminate in a Special Observing Period (MAP-SOP) from September to November 1999 .

All the above aspects served to motivate the establishment and definition of a research project under the title "Heavy precipitation in the Alpine region (HERA)", which was submitted to the "hydrological risks" topic within the EU 
Table 1. Distribution of the Workshare Between the Six Work Packages and the Nine Partner Institutions Introduced in

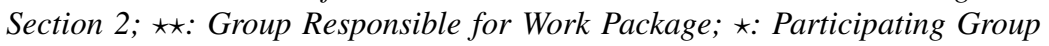

\begin{tabular}{|c|c|c|c|c|c|c|c|c|c|}
\hline \multirow{2}{*}{$\begin{array}{l}\text { Country } \\
\text { Institution }\end{array}$} & \multicolumn{2}{|c|}{$\mathrm{DE}$} & \multicolumn{2}{|c|}{ AT } & \multirow{2}{*}{$\begin{array}{l}\text { CH } \\
\text { ETH }\end{array}$} & \multicolumn{2}{|c|}{ IT } & \multicolumn{2}{|c|}{ FR } \\
\hline & DLR & MIM & IMGW & IMGI & & FISBAT & SMR & CNRM & LA \\
\hline A1 & $\star \star$ & & $\star$ & & $\star$ & & & & \\
\hline A2 & & & & & & & $\star$ & $\star \star$ & \\
\hline A3 & $\star$ & $\star$ & & $\star \star \star$ & & $\star$ & $\star$ & & \\
\hline B1 & & & & & & & & & $\star \star$ \\
\hline B2 & & & & & & & & $\star \star$ & $\star$ \\
\hline B3 & & $\star$ & & & $\star \star$ & $\star$ & & & \\
\hline
\end{tabular}

research programme "environment and climate". Project HERA officially started on 1 December 1996 and continued till 31 March 1999. The reminder of the present overview article outlines the project's aims and structure of six workpackages (section 2), highlights major project results (section 3) and attempts a balanced conclusion and outlook (section 4). Detailed accounts on the various results obtained during the conduct of HERA are given in the other articles of this volume.

\section{Project Aims and Structure}

The Alpine region consisting of the numerous massifs divided by deep valleys and the adjacent foreland were selected as the geographical focus of a truely European dimension. Furthermore it was decided to concentrate on a number of recent, but past precipitation episodes and to make use of a variety of available data types which had been collected independent of HERA.

Nine institutions from five Alpine countries made up the partnership: from Germany (DE) DLR Oberpfaffenhofen, Institut für Physik der Atmosphäre and Meteorologisches Institut der Universität München (MIM); from Austria (AT) Institut für Meteorologie und Geophysik der Universität Wien (IMGW) and Institut für Meteorologie und Geophysik der Universität Innsbruck (IMGI); from Italy (IT) Istituto di Scienze dell'Atmosfera e dell'Oceano (till 1998: FISBAT), and Servizio Meteorologico Regionale (SMR), both in Bologna; from France (FR) Centre National de Recherches Météorologiques (CNRM) of Météo-France and Laboratoire d'Aérologie (LA) of Université Paul Sabatier, both in Toulouse; and from Switzerland $(\mathrm{CH})$ Institut für Atmosphärische Wissenschaft and Geographisches Institut of ETH, Zürich.
The overall objectives of the project were defined as follows:

- to establish a multi-year systematic collection of heavy precipitation episodes by processing combined data sets from ground based radar, surface and upper air observations;

- to analyse major precipitation events by applying operational and research-type numerical weather forecast models and to quantify the underlying physical processes;

- to adapt airborne radar algorithms to measurements over mountainous terrain; and

- to develop and to implement new highresolution numerical techniques (nonhydrostatic grid nesting).

More specifically, answers to questions such as the following ones were sought:

- What is the spatial extent and temporal duration of severe precipitation events in the Alpine region?

- How predictable are such events using operational mesoscale NWP models?

- Which are the essential dynamical processes for engendering copious precipitation in mountainous terrain? Does the relative importance of forcing processes differ between the northern and southern flank of the Alps? How important are amplification effects through synchronous processes acting in different height levels?

- What can be gained from observational and modelling techniques under development? Which spatial and temporal data resolution can be realistically expected by hydrologists, geologists and warning services?

The entire work share was split in a project structure consisting of six work packages to 
which the partners were to contribute as given in Table 1:

A1: systematic monitoring of precipitation systems from recent years;

A2: coherent evaluation of operational precipitation forecasts;

A3: detailed investigation of major cases;

B1: feasibility of airborne Doppler radar techniques over complex orography;

B2: implementation of advanced modelling techniques; and

B3: process studies of basic mechanisms.

The work packages A1, A2, A3 placed the emphasis on observed cases and the application of established techniques, while packages B1, B2, B3 concentrated on process studies of key physical mechanisms and advanced techniques which are under development.

Regarding the applied methods the project aimed at a balanced blend of

observations from

- advanced ground based radars (some Dopplerized/polarmmetric),

- routine surface networks (partly automatted),

- routine upper air soundings; and

\section{simulations from}

- operational weather forecasting models,

- research models concentrating on key mechanisms,

- tests of the coming generation of operational models

in order to obtain an as complete as possible picture of heavy precipitation events in the Alpine region and the short range predictability for the atmospheric part of the hydrological cycle.

\section{Key Results}

This section outlines what is considered to be the prinpical achievements made in the course of HERA. The sequence of presentation follows the structure of work packages as described above. More details can be found in the bulk of all the referenced papers, which are also contained in this volume of Meteorology and Atmospheric Physics.

\subsection{Systematic Monitoring}

For a long time rain gauge networks served as the standard tool for precipitation monitoring. Although they usually have the highest spatial density of all meteorological surface networks, a reliable quantification of areal precipitation is hampered by their modest temporal resolution (merely daily sums at the vast majority of stations) and by the inadequacy of point measurements for the determination of a field as highly structured as rainfall.

During the past 40 years radar techniques have been more and more refined and are now operationally used to determine quasi-instantaneous rain rates from the echoes that precipitating particles generate when hit by micro-wave electro-magnetic radiation which had been emitted from a radar installation (Austin, 1999). Most meteorological services now cover their domains with radar networks. But routine transnational links were hardly available in the Alpine region before the start of HERA.

Hagen et al. (this volume) outline the combined use of radar data from France, Switzerland, Germany, and Austria and of a 25 year daily precipitation climatology (Frei and Schär, 1998; augmented by the years 1991-95) to monitor development, progression and spatial extent of mesoscale convective systems (MCS) along the northern side of the Alps. Nine precipitation episodes were selected from the years 1992,94, 95, 96 in order to construct HERA radar composites combining data of up to twenty radars covering an area of about $1,250 \times 650 \mathrm{~km}^{2}$. A grand total of 1104 half-hourly pictures have been produced spanning a period of 23 days. All pictures (GIF-format) and datafiles are collected in the user section of the MAP Data Centre at ETH Zürich (http://map.ethz.ch/mm-doc/ HERA.htm).

The four panels of Fig. 5 span $4.5 \mathrm{~h}$ and clearly depict complexity, size and propagation speed of a semi-coherent precipitation pattern with much variability in the appearance (and disappearance) of convective cells. Hagen et al. (this volume) give statistical details about, inter alia, size, duration and total rain volume for all $15 \mathrm{MCS}$ which occured during the selected HERA episodes. On 22 July 1995, for instance, more than $5 \cdot 10^{9} \mathrm{~m}^{3}$ rainfall were determined from the 

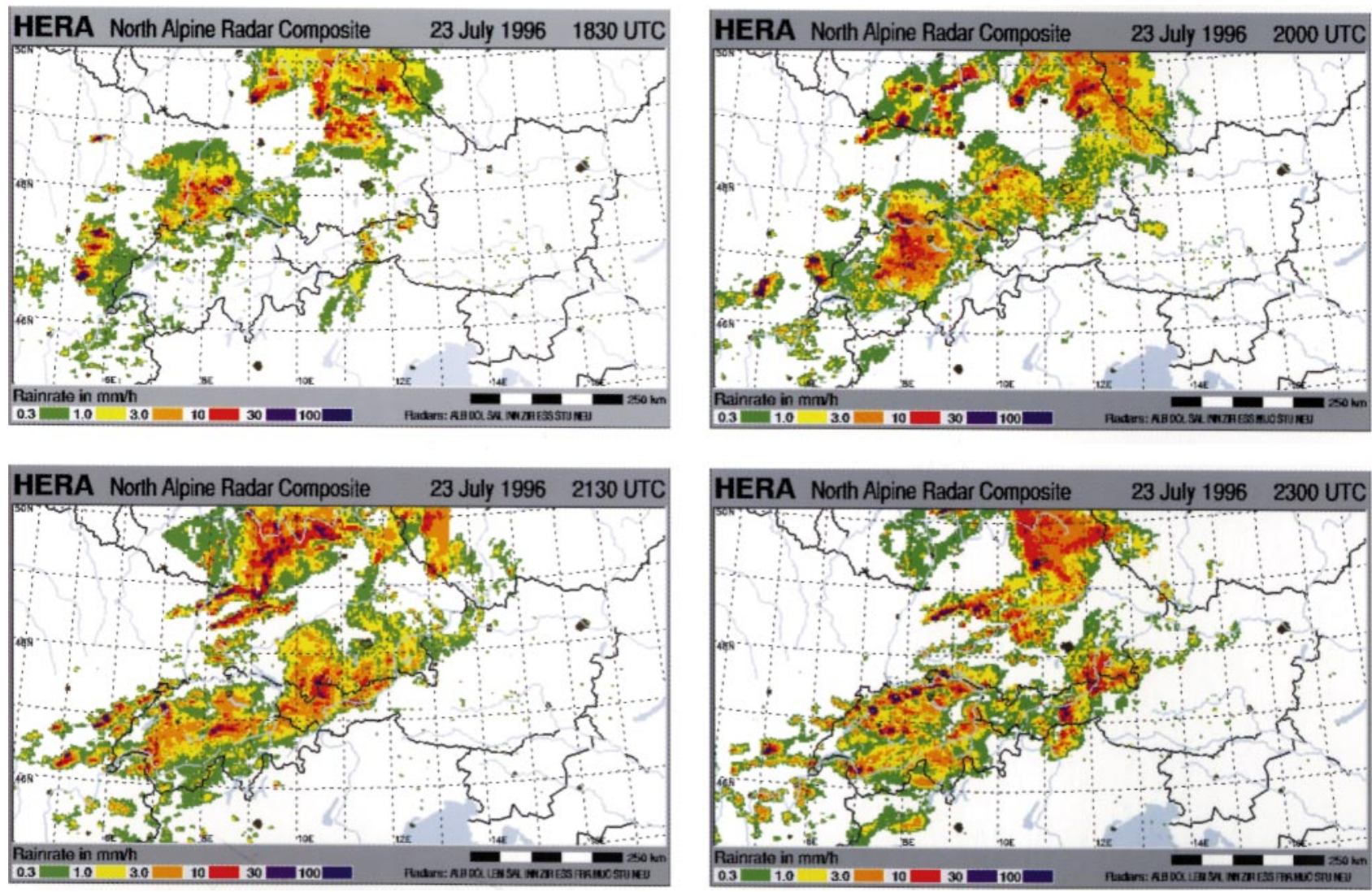

Courtesy: Martin Hagen

Fig. 5. Time evolution (with $1.5 \mathrm{~h}$ intervals) of the convective cells (red and purple) imbedded in a multiline frontal system on 23 July 1996. The varying number of available radars ( 8 to 11) should be noted

radar measurements during little more than $8 \mathrm{~h}$. From the combination of several years of radar data and longer term rain gauge measurements it was estimated that a large MCS (more than $30 \mathrm{~mm} / \mathrm{d}$ precipitation over an area of more than $40,000 \mathrm{~km}^{2}$ ) has to be expected in the northern Alpine region every 6 years.

An automatted monitoring of convective cells within MCS is possible through a combination of radar measurements with data from lightning detection systems operated by electricity providers (Steinacker et al., this volume). Preferred tracks were found along large Alpine valleys and their flanks.

\subsection{Coherent Evaluation of Operational Forecasts}

Although numerical weather prediction with electronic computers has a nearly 50 year history, operational forecasts including mesoscale precipition fields only became generally available during the past decade. The explorative study of Nickerson et al. (1986) already stressed the necessity for a combined view of airflow over mountains and precipitation, but also demonstrated the considerable difficulties of a consistent model evaluation. If forecast precipitation fields are eventually to be used for hydrological warning schemes, a strigent short term quality assessment of operational precipitation forecasts is mandatory.

A, perhaps unexpected, difficulty consists in the provision of a reliable calibration standard, i.e. a consistent, quality controlled, daily precipitation climatology for horizontal areas comparable with the computational gridsize as only recently put forward by Frei and Schär (1998). Mladek et al. (this volume) use this information together with daily data provided by the forecasting centres of Deutscher Wetterdienst (DWD; Offenbach), Météo-France (Toulouse), Servicio Meteorologico Regionale (Bologna), and Schweizerische Meteorologische Anstalt 

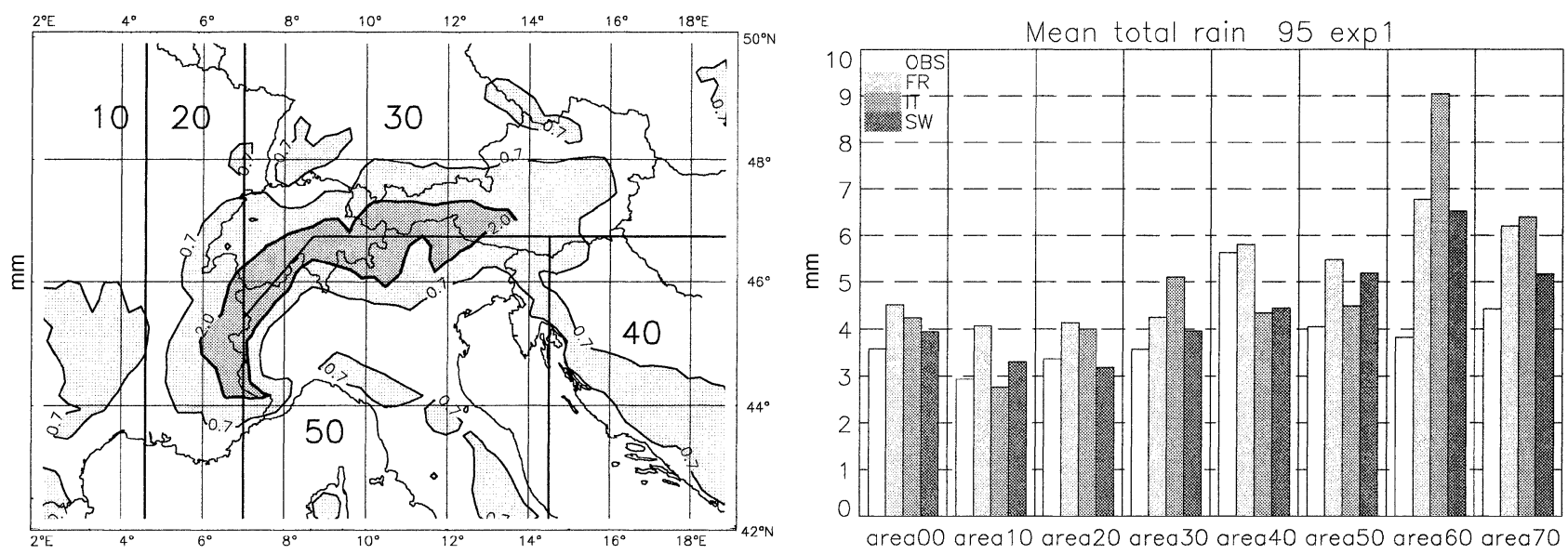

Courtesy: Philippe Bougeault

Fig. 6. Summary of intercomparison of operational precipitation forecasts. Left: Total area (00) and subareas used for the intercomparison over 164 days in autumns 1995 and 1996: Massif Centrale (10), western Alps (20), northern Alps (30), Dinaric Alps (40), southern Alps (50), elevations above $2000 \mathrm{~m}$ (60; dark grey), and elevations above $700 \mathrm{~m}$ (70; light and dark grey). Right: Observed versus forecast mean daily precipitation $(\mathrm{mm} / \mathrm{d})$ by (sub)areas and agency: Météo-France (FR), Servizio Meteorologico Regionale (IT), and Schweizerische Meteorologische Anstalt (SW)

(Zürich) for parts of the MAP seasons in autumn 1995 and 1996. The complete analysis domain and its division in subareas is shown in Fig. 6 together with the respective mean forecast quality for the test period in 1995. In general the models are able to reproduce the observed precipitation with some tendency of overprediction. The latter is most striking for subarea 60 of elevations exceeding $2000 \mathrm{~m}$. This finding in itself stresses the importance of a special observing period of measurements with a spatial and temporal resolution much enhanced over routine practise, as it will be undertaken in autumn 1999 within MAP. But it also points to possible uncertainties in the observational database for high Alpine elevations.

Mladek et al. (this volume) present a wealth of statistical information in charts, scatter plots, global skill scores for various thresholds and sample time-series of these. They also attempt a classification of precipitation events depending on the predominant wind direction. Thus work package A2 was successful in providing a first large step towards a systematic quality control and model intercomparison procedure for precipitation forecasts, especially over mountainous terrain. However remaining technical barriers also became evident, as resolution and duration of the observational database has to be increased together with longer archived series of consistent model results, i.e. those not influenced by the ongoing modifications in the forecasting systems. The European meteorological services are encouraged to seriously consider the conduct of a multiyear re-analysis project for central Europe following the global scale example of the European Centre for Medium-range Weather Forecasts (ECMWF; Gibson et al., 1997). As a side-effect this would certainly ease the access to hitherto neither easily nor inexpensively available high resolution European climate data (Hulme, 1994).

\subsection{Detailed Case Studies}

Precipitation episodes with flooding potential are rare and mostly single events. Therefore a closer inspection of capabilities and current limiting factors of some European operational NWP models is approriate for such episodes.

Buzzi and Foschini (this volume) apply the research NWP model BOLAM3 to five recent flooding episodes on the southern-western to south-eastern flanks of the Alps. They investigated the impact of variable horizontal grid resolution from 40 down to $4 \mathrm{~km}$ and found an increase of simulated rainfall amounts for finer resolutions but no statistical significance (due to the small sample size).

Cacciamani et al. (this volume) use the operational model LAMBO of the regional meteorological service (SMR) of the Italian 


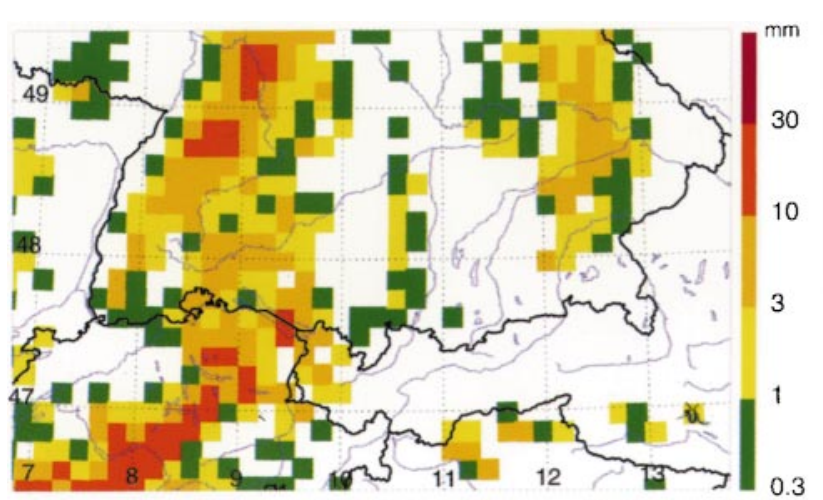

1 hour RR: 16-17 UT

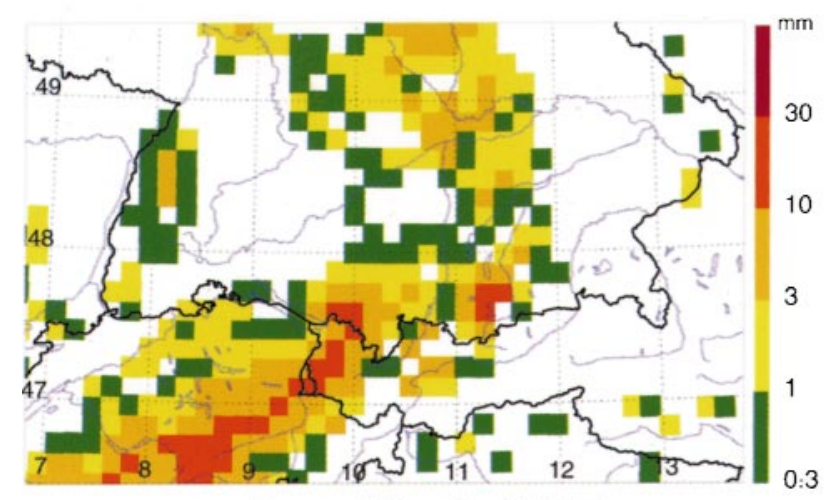

1 hour RR: 18-19 UT

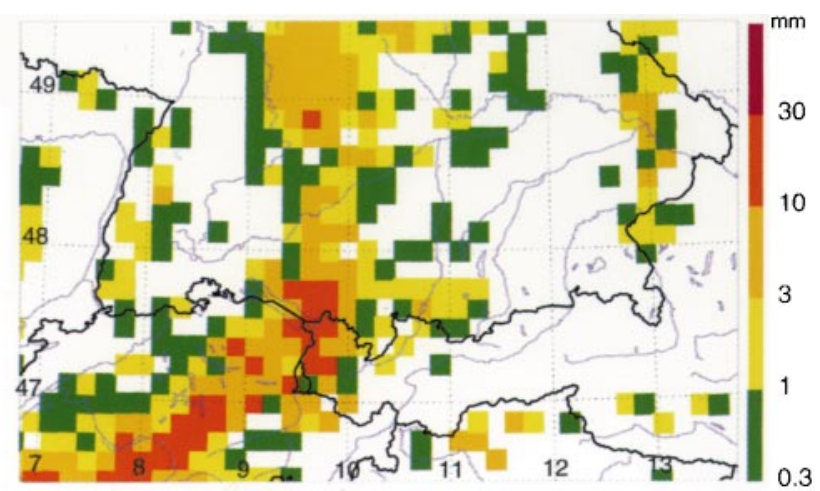

1 hour RR: 17-18 UT

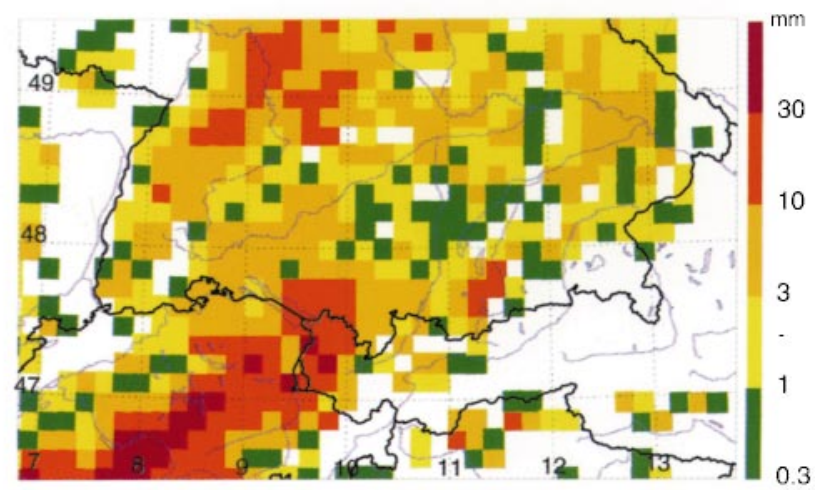

3 hour RR: 16-19 UT

Courtesy: Christian Keil

Fig. 7. Transient nature of precipitation over the north Alpine foreland as simulated for three consecutive hourly intervals on 5 July 1996 and the resulting three-hourly precipitation (RR)

region Emilia-Romagna for numerical experiments of three south-Alpine flooding events. Beside the effect of horizontal resolution they focus on the sensitivity of the simulated rainfall to the specified initial conditions. A newly developed nudging scheme, which allows to input detailed surface observations into the simulation run, helps to provide better results, especially regarding the fine scale structure of the precipitation patterns.

Keil and Volkert (this volume) apply the research version of DWD's Deutschland Modell (DM) to four of the north-Alpine cases which were selected for the HERA radar composites (see subsection 3.1). The model independent validation data comprise the regular raingauge network of DWD, the HERA composites, Doppler winds from the DLR research radar, and meteorological time series at a ground station.

Three consecutive hourly precipitation amounts and the resulting three-hourly sum (Fig. 7) reveal: the quite transient nature of a precipitation field linked to a cold front passage; the nevertheless spotty nature of the calculated rain amounts made up of grid-mesh pixels sized $14 \times 14 \mathrm{~km}^{2}$ (eight pixels equal $1^{\circ}$ difference in latitude); and the local three-hourly maxima execeeding $10 \mathrm{~mm}$ across Switzerland as well as in the region of rivers Neckar and southern Isar. A four-day budget evaluation from hourly simulation data over the Isar-Amper catchment (made up of 45 grid-meshes) involves the atmospheric moisture terms, the resulting convective and grid-scale precipitation components and areal weighted upward motion. It demonstrates both the potential and the present (spatial) limitations of this current atmospheric forecasting system.

Hofinger et al. (this volume) report about a finescale investigation of 14 summer-time precipitation events from 1997 in the intra-Alpine region around Innsbruck. The study included the set up of a dedicated network with 5 to $10 \mathrm{~min}$ recording 

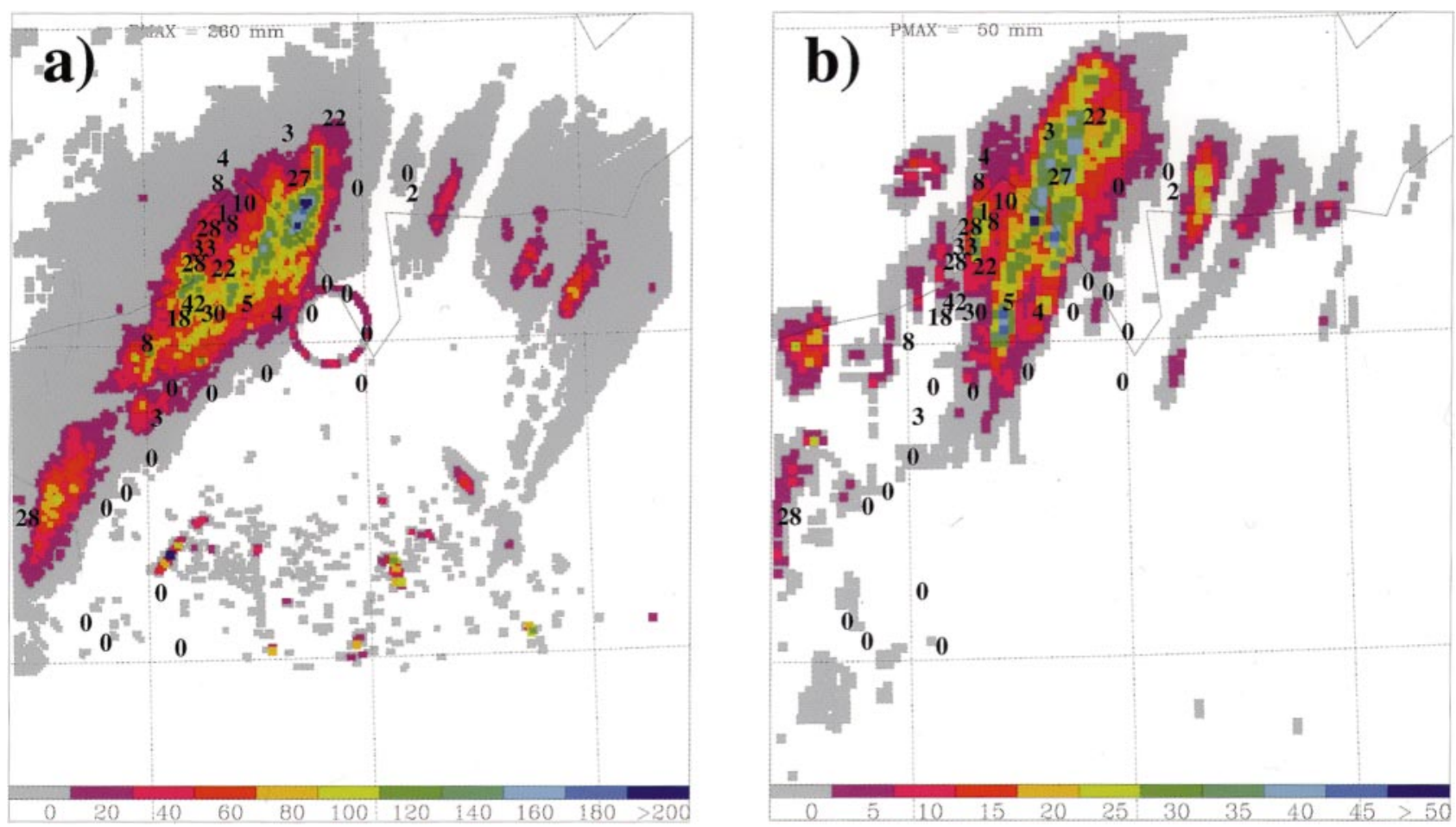

Courtesy: Evelyne Richard

Fig. 8. Six-hourly accumulated rainfall pattern during the Brig flashflood event (22 September 1993, 12 to 18 UT; in mm) as determined from 36 radar measurements from Monte Lema (at $8.8^{\circ} \mathrm{E}, 46.1^{\circ} \mathrm{N}, 1620 \mathrm{~m}$; a) and by a high resolution simulation including ice-phase parameterizations (b). The numbers $(\mathrm{mm})$ denote rain gauge measurements from Italian and Swiss stations. See text for the discrepancy in colour scale. The $1^{\circ} \times 1^{\circ}$ grid (centre at $9^{\circ} \mathrm{E}, 46^{\circ} \mathrm{N}$ ) and an approximated Italo-Swiss borderline aid the orientation

interval. Rainfall of up to $30 \mathrm{~mm} / 6 \mathrm{~h}$ and distinct gradients over short distances were documented. This material may prove to provide valuable verification material for future simulations when large inner-Alpine valleys can be resolved.

\subsection{Feasibility of Doppler Radar Techniques}

The preceeding subsections indicated that more detailed and accurate observations of strong precipitation systems are still necessary in order to improve the simulation capabilities. Doppler radars have the unique capacity to provide simultaneous information about the flow and precipitation fields. In the past, algorithms for flow determination were not well suited for applications near highly variable orography, as unaccounted ground clutter and orographically induced small scale circulations deteriorated the retrieved wind information. The additional advantage of an airborne system, i.e. movable around the area of interest, could up to now only be applied over sea or flat terrain.

Georgis et al. (this volume) present extended retrivial algorithms including variational methods for ground-based and airborne dual Doppler radar measurements over complex terrain, such as the Alps or the Rocky Mountains. A hierarchy of tests is preformed, which comprise radar observations for analytically specified flows over idealized terrain, numerically simulated wind and reflectivity fields for the Brig flood event (22 September 1993; see also Stein et al., this volume), and actual measurements during a shower episode over the Colorado Rockies.

During the MAP-SOP in autumn 1999 several American and French teams will operate groundbased and airborne Doppler-radars particularly in the region around Lago Maggiore (Fig. 4). Then these new methods are indispensible for a detailed documentation of the life-cycle of orographically and convectively induced storms. 


\subsection{Advanced Modelling Techniques}

Already during the definition phase of HERA it was felt that the new generation of meso-scale NWP model, which then started to be developed, will offer good prospects for a distinct progress in quantitative rainfall forecasting. The following three features are considered important for a realistic and well resolved simulation of precipitation over complex terrain: (i) the application of a prognostic equation for the vertical velocity (non-hydrostatic model; in contrast to current hydrostatic models which diagnose upward motion from a more approximated version of mass continuity); (ii) the use of mesh sizes clearly below $10 \mathrm{~km}$ (by interactive grid nesting); and (iii) the inclusion of ice phase processes in the microphysical parameterizations. All these points are being combined in the Meso-NH model.

Stein et al. (this volume) give a brief technical description of these novel features and present systematic sensitivity studies comprising about 10 numerical experiments for each of the flooding events of Vaison-La-Romaine (22 September 1992) and Brig (22-24 September 1993). Special efforts were undertaken to obtain improved initial conditions, e.g. by indirectly inferring the moisture structure over the Golfe du Lion from infrared satellite imagery, to obtain sixhourly rainfall amounts from Italian and Swiss rain gauges (with the kind assistance of the EUfellow project RAPHAEL), and to determine radar rainfall estimates from the early test phase of the Monte Lema radar in southern Switzerland.

Six-hourly accumulated rainfall during the Brig episode from three independent data sources are jux-taposed in Fig. 8. The raingauge data (black numbers) are seen as reliable point information revealing the distinct local maxima $(42 \mathrm{~mm} / 6 \mathrm{~h}$ in the more central part; $28 \mathrm{~mm} / 6 \mathrm{~h}$ at the western edge) and the border to areas which remained dry. The summed-up radar information (Fig. 8a) gives the two-dimensional banded structure of the precipitation field with a double core wide band west of the 9th meridian and three slim ones east of it. The northern edge of the strong maximum is apparently underestimated, probably due to beam blocking by intermediate summits. Altogether the radar derived rain rates are too high by about a factor of 4 (due to calibration problems during the early operational phase of the radar in 1993; Martin Hagen: personal communication) Therefore the colour scale was adjusted accordingly.

The Meso-NH simulation result with $2.5 \mathrm{~km}$ horizontal resolution and including ice-phase microphysics (Fig. 8b) contains the following important features: the model mesh-size is approaching the size of the radar pixels; the banded structures are well captured including the narrow dry zones; the quantitative agreement with the surface observations is remarkable; the northward extent of the wide band is different from the radar information, but coincides well with the surface data. Having in mind the complex orography of the area (Fig. 4), it is important to note the decisive interplay between mountain induced vertical circulations, the generation of precipitation and the possible spillover across mountain chains into different catchments (as it was the case in Brig situated well north of the observed and simulated precipitation maximum). It appears that in this respect the advanced modelling techniques will attain great additional value in the future.

\subsection{Basic Mechanisms}

A project dealing with the current state of research regarding the determination and simulation of areal precipitation would be incomplete, if it did not include studies dealing with the basic mechanisms involved and intrinsic difficulties which impede large gains in model skill.

Fehlmann and Quadri (this volume) indicate that the vast majority of severe rainstorms, in particular on the Alpine southside, was to a good measure determined by anomalies in atmospheric levels high above the mountains. Consistent variation of upper level structures within the accuracy of routine measurements in this region reveals a remarkable impact on amount and location of simulated precipitation maxima. This leads to the hypothesis that misforecasts are to some extent due to the insufficiently known atmospheric state well above and a day or two prior to a severe precipitation event. Realistic hindcast simulations are carried out for the entire five October months of the years 1987-90 and 1992. All strong south-Alpine precipitation 
events contained in the period exhibit a very similar synoptic scale structure at upper levels. This aids the definition of more refined observational strategies which will be tested during the MAP-SOP in autumn 1999.

Inspired by the severe precipitation event, which induced the Piedmont flood of November 1994, Schneidereit and Schär (this volume) carry out a hierarchy of idealized numerical experiments with dry and moist atmospheres and different approximations of the arc-shaped Alpine orography. The importance of a high velocity (jet) flow at lower levels and the Earth's rotation (Coriolis effect) for sufficiently strong lifting becomes evident as well as the rôle of the Alpine arc for the concentration of precipitation in a comparatively small area.

Peristeri et al. (this volume) investigate the genesis conditions for thunderstorms and squall lines at the Alpine north-side by taking basic parameters from the 1994-HERA-cases. Especially in summer large-scale south-westerly flow transports low-level moisture from the Mediterranean around the western Alps to southern Germany where mountain-induced wave effects tend to trigger convective instability. Frequently occurring pre-frontal convergence-lines are shown to have a significant impact on the strength of thunderstorm forming convective cells.

Fantini and Davolio (this volume) report on an attempt towards a theoretical treatment of the combined study of atmospheric frontal zones, which generate uplift and precipitation, and isolated orography.

\section{Conclusions}

On the term of HERA numerous innovative and valuable conclusions can be drawn and these are recorded below.

Several important technical achievements were made concerning the areal rainfall determination over complex terrain, as the setup of transnational radar composites (meanwhile also available as real time application), a first objective quality assessment of operational mesoscale precipitation forecasts, the development of extended Doppler radar retrieval algorithms, or the successful demonstration of high resolution forecasts including ice-phase processes. Computerized deliverables are available to interested parties via the MAP Data Centre at ETH, Zürich.

Tangible answers were found to the questions which had been put forward at the outset of the project. The size of strong precipitation events regularly exceeds $10,000 \mathrm{~km}^{2}$. At the northern side of the Alps a west-to-east propagation is most frequent, while the Alpine shape has the potential to lock precipitation systems on its southern side over a relatively small area for several days. Current NWP systems exhibit growing skill in simulating precipitation, but a reliable ground truth is not generally available, especially for higher elevations. Nearly all strong rainfall events are a complicated interplay of several atmospheric mechanisms. South-Alpine events are regularly triggered by upper level anomalies. The coming generation of NWP systems will provide routine forecasts with meshsizes of a few square-kilometres for, say, three-hourly periods.

Project HERA much profited from being fully integrated in the ungoing Mesoscale Alpine Programme (MAP) with its pre-established contacts between the partners of the consortium. The significant, but still only partial (about 55\%) funding by the CEC proved to be extremly important to further strengthen these research links and to enable notably younger scientists to become involved into a truely European co-operation.

Concerning interdisciplinarity good integration was achieved between the diverse disciplines in the atmospheric sciences, as radar engineering, high-end numerical modelling, micro-physics, or conventional data collection. But any follow-on project in the flood-forecasting domain has to install close links with the hydrological modelling community. Furthermore, the emphasis is to be shifted closer towards integrated applications for specific cases (for a recent example in Canada see Benoit et al., 2000).

As a natural outlook we envisage the collection of atmospheric and hydrological data in unprecedented spatio-temporal resolution during the MAP-SOP in autumn 1999, partly by making use of techniques which were developed within HERA. These then await their use in a convincing demonstration of what integrated atmospheric and hydrological forecasts should be able to routinely achieve in the not too distant future to the benefit of many of the well over 10 millions 
inhabitants of the Alpine region; all the more, as intense precipitation events are likely to become even more frequent (Frei et al., 1998; Karl and Häeberli, 1998).

\section{Acknowledgements}

As the coordinator of project HERA it is the author's pleasure to explicitly acknowledge the dedicated efforts of all partners of the consortium to achieve the common research aims as they had been envisaged during the planning process and to make available their results. Gerhard Berz, Angelika Wirtz (Munich Re, München) and Remo Cavalli (SMA, Locarno) kindly granted background information. Ian Cluckie (Univ. of Bristol) generously provided a preprint of the proceedings from a recent Advanced Study Course on real time flood forecasting. Huw Davies (ETH Zürich) patiently ameliorated a foreigner's use of English. Winfried Beer, Martin Leutbecher, and Anja Trudel (DLR, Oberpfaffenhofen) gave valuable technical assistance for the layout of text and figures. This study was in parts supported by the European Commission, Programme "Environment and Climate" under contract ENV4-CT96-0332.

\section{References}

Austin, G. L., 1999: History of radar and radar metorology. In: Griffith, R. J., Cluckie, I. D. (eds.) Radar Hydrology for Real Time Flood Forecasting. Proceed. Advanced Study Course, European Commission, Luxembourg, in press, $11 \mathrm{pp}$.

Binder, P., Schär, C. (eds.), 1995: Mesoscale Alpine Programme: Design Proposal. Swiss Meteorological Institute, Zürich, 77 pp.; second edition 1996; available also from http://map.ethz.ch/proposal.htm.

Benoit, R., Pellerin, P., Kouwen, N., Ritchie, H., Donaldson, N., Joe, P., Soulis, R., 2000: Toward the use of coupled atmospheric and hydrologic models at regional scale. Mon. Wea. Rev. (accepted).

Buzzi, A., Foschini, L., 2000: Mesoscale meteorological features associated with heavy precipitation in the southern Alpine region. Meteorol. Atmos. Phys., 72, 131146.

Cacciamani, C., Cesari, D., Grazzini, F., Paccagnella, T., Pantone, M., 2000: Numerical simulation of intense precipitation events south of the Alps: Sensitivity to initial conditions and horizontal resolution. Meteorol. Atmos. Phys., 72, 147-159.

Casale, R., Pedroli, G., Samuels, P., 1998: Current policy and practice on flood mitigation. Introduction to River basin modelling, management, and flood mitigation concerted action. Workshop Proceed. EUR 18019 EN, European Commission, Luxembourg, ISBN 92-828-2002-5, 1-3.

Cluckie, I. D., 1998: General conclusions of First RIBAMOD Workshop. In: Casale, R., Pedroli, G. B., Samuels, P. (eds.) River Basin Modelling, Management, and Flood Mitigation Concerted Action. Workshop Proceed. EUR
18019 EN, European Commission, Luxembourg, ISBN 92-828-2002-5, 384.

Cluckie, I. D., 1999: An overview of real time flood forecasting. In: Griffith, R. J., Cluckie, I. D. (eds.) Radar Hydrology for Real Time Flood Forecasting. Proceed. Advanced Study Course, European Commission, Luxembourg, in press, $16 \mathrm{pp}$.

Cluckie, I.D., Han, D., 1995: Weather radar information processing in real-time for flood forecasting. In: HorlickJones, T., Amendola, A., Casale, R. (eds.) Natural Risk and Civil Protection. E \& FN Spon, London, ISBN 0-419-19970-5, 226-236.

Fantini, M., Daviolo, S., 2000: Formulation of a semigeostrophic model of frontal interaction with isolated orography. Meteorol. Atmos. Phys., 72, 261-270.

Fehlmann, R., Quadri, C., 2000: Predictability issues of heavy Alpine south-side precipitation. Meteorol. Atmos. Phys., 72, 223-231.

Frei, C., Schär, C., 1998: A precipitation climatology of the Alps from high-resolution rain-gauge observations. Int. J. Climatol., 18, 873-900.

Frei, C., Schär, C., Luthi, D., Davies, H. C., 1998: Heavy precipitation in a warmer climate. Geophys. Res. Lett., 25, 1431-1434.

Garrote, L., 1995: Flood vulnerability assessment and management. In: Horlick-Jones, T., Amendola, A., Casale, R. (eds.) Natural Risk and Civil Protection. E \& FN Spon, London, ISBN 0-419-19970-5, 213-225.

Georgis, J. F., Roux, F., Hildebrand, P., 2000: Observation of precipitating systems over complex orography with meteorological Doppler radars: A feasibility study. Meteorol. Atmos. Phys., 72, 185-202.

Gibson, J. K., Kållberg, P., Uppala, S., Hernandez, A., Nomura, A., Serrano, E., 1997: ECMWF Re-Analysis description. ERA Project Series 1, ECMWF, Reading $72 \mathrm{pp}$.

Hagen, M., Schiesser, H.-H., Dorninger, M., 2000: Monitoring of mesoscale precipitation systems in the Alps and the northern Alpine foreland by radar and raingauges. Meteorol. Atmos. Phys., 72, 87-100.

Hofinger, S., Mayr, G. J., Dreiseitl, E., Kuhn, M., 2000: Finescale observation of summertime precipitation in an Intra-Alpine region. Meteorol. Atmos. Phys., 72, 175184.

Horlick-Jones, T., Amendola, A., Casale, R. (eds.), 1995: Natural Risk and Civil Protection. E \& FN Spon, London, ISBN 0-419-19970-5, xiv + 554 pp.

Hulme, M., 1994: The cost of climate data - a European experience. Weather, 49, 168-175.

Karl, T. R., Haeberli, W., 1998: Climate extremes and natural disasters: Trends and loss reduction prospects. In: Bruce, J. P. (ed.) World Climate Research Programme: Achievements, Benegits and Challenges. WMO/TD No. 904, Geneva, 166-178.

Keil, C., Volkert, H., Majewski, D., 1999: The Oder flood in July 1997: Transport routes of precipitable water diagnosed with an observational forecast model. Geophys. Res. Lett., 26, 235-238.

Keil, C., Volkert, H., 2000: Precipitation in the northern Alpine region: Case-study type validation of an opera- 
tional forecast model. Meteorol. Atmos. Phys., 72, 161173.

Marcuello, C., 1998: Understanding flash flood experiences. In: Casale, R., Pedroli, G. B., Samuels, P., (eds.) River Basin Modelling, Management, and Flood Mitigation Concerted Action. Workshop Proceed. EUR 18019 EN, European Commission, Luxembourg, ISBN 92-828-2002-5, 37-41.

Mladek, R., Barckicke, J., Binder, P., Bougeault, P., Brzovic, N., Frei, C., Geleyn, J. F., Hoffman, J., Ott, W., Patruno, P., Pottier, P., Rossa, A., 2000: Intercomparison and evaluation of precipitation forecasts for MAP seasons 1995 and 1996. Meteorol. Atmos. Phys., 72, 111-129.

Moore, R. J., 1998: Flood hazard research within the European Commission 1987 to 1996. In: Casale, R., Pedroli, G. B., Samuels, P. (eds.) River Basin Modelling, Management, and Flood Mitigation Concerted Action. Workshop Proceed. EUR 18019 EN, European Commission, Luxembourg, ISBN 92-828-2002-5, 7-22.

Nickerson, E. C., Richard, E., Rosset, R., Smith, D. R., 1986: The numerical simulation of clouds, rain, and airflow over the Vosges and Black Forest mountains: A meso- $\beta$ model with parameterized microphysics. Mon. Wea. Rev., 114, 398-414.

Persteri, M., Ulrich, W., Smith, R. K., 2000: Genesis conditions for thunderstorms growth and the development of a squall line in the northern Alpine foreland. Meteorol. Atmos. Phys., 72, 251-260.
Quiby, J., Schubiger, F., 1998: Quality assessment of the meteorological computer forecasts for localized flash floods. In: Casale, R., Pedroli, G. B., Samuels, P. (eds.) River Basin Modelling, Management, and Flood Mitigation Concerted Action. Workshop Proceed. EUR 18019 EN, European Commission, Luxembourg, ISBN 92-8282002-5, 73-79.

Schneidereit, M., Schär, C., 2000: Idealized numerical experiments of Alpine flow regimes and southside precipitation events. Meteorol. Atmos. Phys., 72, 233-250.

Stein, J., Richard, E., Lafore, J. P., Pinty, J. P., Asencio, N., Cosma, S., 2000: High-resolution non-hydrostatic simulations of flash-flood episodes with grid-nesting and icephase parameterization. Meteorol. Atmos. Phys., 72, 203221.

Steinacker, R., Dorninger, M., Wölfelmaier, F., Krennert, T., 2000: Automatic tracking of convective systems from lightning and radar data. Meteorol. Atmos. Phys., 72, 101-110.

Volkert, W. (ed.), 1983: Handbuch der bayerischen Ämter, Gemeinden und Gerichte 1799-1980. C. H. Beck, München, ISBN 3-406-09669-7, xxxiv +705 pp.

Author's address: Hans Volkert, DLR Oberpfaffenhofen, Institut für Physik der Atmosphäre, D-82234 Wessling, Germany (e-mail: Hans.Volkert@dlr.de). 